\section{artelogie}

\section{Artelogie}

Recherche sur les arts, le patrimoine et la littérature de l'Amérique latine

12 | 2018

Idiosyncrasie de l'indigénisme en Amérique latine.

Pluralité des sources et des appropriations extra-

latino-américaines

Olhares Sensiveis: as Belezas das Cidades e suas Barbáries. NOVOA, Jorge; FRESSATO, Soleni. Curitiba, Editora Prismas, 2018.

Catarina Cerqueira de Freitas Santos

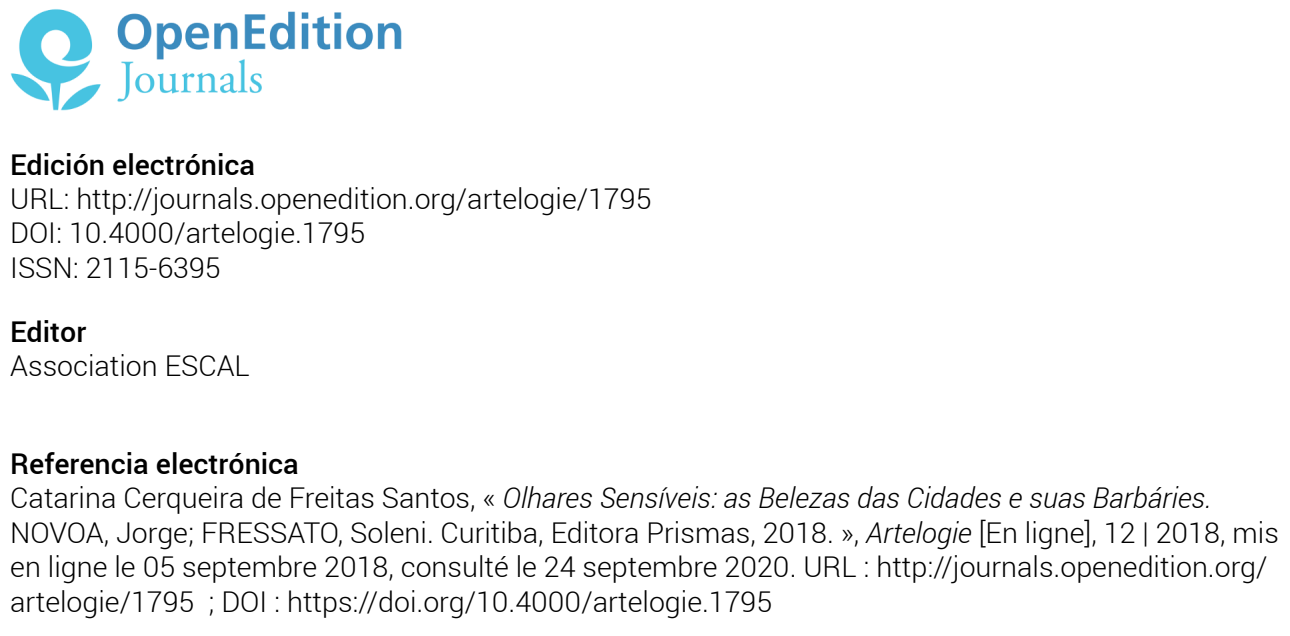

Este documento fue generado automáticamente el 24 septembre 2020

Association ESCAL 


\title{
Olhares Sensíveis: as Belezas das Cidades e suas Barbáries. NOVOA, Jorge; FRESSATO, Soleni. Curitiba, Editora Prismas, 2018.
}

\author{
Catarina Cerqueira de Freitas Santos
}

Passados quase cinquenta anos desde que Marc Ferro, através dos seus estudos pioneiros, estabeleceu que o filme é uma contra-análise da sociedade, sendo uma fonte historiográfica fundamental para revelar as contradições e inconscientes de sociedades que se representam através de sons e imagens em movimento, muitos estudos já reconhecem o cinema, e outras mídias, como instrumento de análise social e histórica imprescindível para as reflexões contemporâneas. Eis que o próprio Ferro apresenta no prefácio do livro Olhares Sensíveis: as Belezas das Cidades e suas Barbáries, a terceira geração de estudiosos da relação cinema-história: aqueles que além de um olhar analítico e reflexivo, também apresentam um olhar sensível sob o cinema. O olhar sensível é aquele que rompe com a visão cartesiana de aparência e essência, de emoção e razão. No livro em questão, esse olhar oferece, tendo como base a lente cinematográfica, as visões contraditórias e complementares sobre as cidades, entre o caos e a ordem, a beleza e a barbárie. Enquanto linguagem complexa que reinventa o real, o cinema também consegue ler as cidades com suas nuances mais específicas, reconstituindo memórias e construindo novas representações imagéticas, nem sempre intencionais.

2 O livro Olhares Sensíveis: as Belezas das Cidades e suas Barbáries é uma obra coletiva, multidisciplinar e cosmopolita, fruto das investigações de pesquisadores de diferentes partes do Brasil e do mundo. Os organizadores, Jorge Nóvoa e Soleni Fressato, possuem vasta produção sobre a temática do cinema como objeto de análise da sociedade. São coordenadores do Grupo de Pesquisa Oficina Cinema-História e, editores da revista digital o olho Da História, que, há mais de vinte anos, proporciona leitura crítica sobre 
cinema, história, modernidade, crise e tantas outras temáticas latentes nas ciências sociais.

3 Na apresentação do livro, os organizadores traçam a perspectiva teórica que conduzirá a reflexão dos outros autores ao longo dos artigos. A partir de uma referência à uma peça teatral, que contextualiza a situação da solidão do homem nas cidades contemporânea, eles convidam à uma reflexão sobre como a arte - cinema, teatro, poesia, música -, consegue traduzir aspectos das vivências coletivas e particulares nas e das cidades, tão caros aos cientistas, tendo como ponto de partida o sensível e o intangível. Dessa maneira, é mérito deles agregar pesquisadores de diferentes trajetórias e construir um elo que conecta olhares tão necessários e, não menos complementares e sensíveis, sobre as cidades através do cinema e da literatura.

o livro é dividido em três partes. A primeira, intitulada Das Belezas das Cidades e de Suas Feiuras, apresenta textos que dão conta de filmografias que exploram várias cidades mundiais: Paris, Beirute, Madrid, Amsterdam, Berlim, Veneza, além da representação norte americana das cidades colombianas. Destaca-se a elaboração do conceito Cidadescinema, apresentado por José D'Assunção Barros em seu artigo Cidades-cinema: uma análise das distopias urbanas no cinema futurista. $\mathrm{O}$ termo se refere às cidades idealizadas por produções cinematográficas específicas, desempenhando um papel central na narrativa do filme, quase como um personagem, sendo uma cidade totalmente imaginada ou recriada a partir de uma referência real. Para o autor, qualquer cidadecinema é ao mesmo tempo real e imaginária, posto que explora demandas do nosso tempo, tornando-se familiar ao espectador. Assim, é possível criar identificação com a Gotham City, totalmente criada no filme 0 Batman (Tim Burton, 1989), como também com a futurista Los Angeles, existente apenas no filme Blade Runner (Ridley Scoot, 1982)

5 Nesse sentido, tendo por base a boa definição do termo Cidades-Cinema, segue-se a leitura dos textos subsequentes com bastante fluidez, seja através da exploração das filmografias sobre Paris ao longo do século XX, abordadas por Michel Marie no texto Paris vu par..., ou através da interessante abordagem da representação de Beirute no cinema realizada por Elie Yazbek. No artigo A representação da cidade de Beirute no cinema, Yazbek situa as representações cinematográficas ocidentais de Beirute antes e depois das guerras. Chingana-Boyana e Paula Posada também exploram a alteridade e as construções de representações estereotipadas sobre a Colômbia nos filmes hollywodianos em Colômbia, uma república dos trópicos: estereótipos desde o cinema

6 Posteriormente, José Noriega, no seu artigo Espaços Urbanos, imaginários e evolução da cidade de Madri no cinema, traz uma reflexão precisa ao destacar que "o cinema funciona como um espelho em que a cidade se reconhece" (2018, p.89). Sua abordagem encontrará na Madrid dos filmes, um reflexo da evolução histórica da periferia e dos espaços cosmopolitas madrilenos.

7 Ainda sobre cidades europeias, Pietsie Feenstra destaca no seu artigo Amsterdam e Berlim, visualizar as memórias de fronteira depois de 1990 Amsterdam, como o local de encontro e fronteira de várias culturas e identidades, e ao mesmo tempo Berlim, enquanto lugar de memória de fronteiras visíveis e invisíveis. Marcos Silva, encerra esse primeiro bloco de artigos, analisando um clássico do cinema mundial com o belo texto Rir da trágica cidade. A beleza e a verdade de Morte em Veneza.

8 Das grandes metrópoles mundiais para a singularidade das cidades nordestinas, a Parte II do livro, Belezas e Barbárie no Nordeste Brasileira, é composta por quatro artigos que 
comprovam que a beleza das cidades nordestinas e a força do seu povo convivem, dialeticamente, com situações de barbárie.

9 Maria do Socorro Silva Carvalho, no artigo Bahia de Todos os Santos: o filme e a cidade, desloca o olhar do filme ao público e aponta para uma dimensão importantíssima na leitura cinematográfica: a recepção. Em 1960, o filme Bahia de Todos os Santos, do cineasta Trigueirinho Neto, foi lançando em Salvador. 0 artigo explora bem a contradição da representação da cidade com o desejo de ser visto naquela representação. $O$ fato é que a elite baiana não se reconheceu nas imagens de Salvador apresentadas no filme. Como continua não se identificando com o negro, o candomblé e tantas outras manifestações culturais, por mais belas que sejam, por considerarem inferiores e bárbaras. Antônio Câmara e Vitor Neves, também retomam filmografias sobre Salvador, em As imagens do Salvador no cinema: modernidade e tradição, a fim de debater a representação da modernidade baiana seja em filmes da década de 1960, momento em que a cidade estava passando por diversas transformações estruturais, seja no aprofundamento das contradições sociais, expressos na filmografia mais recente.

10 Se em cada lugar do mundo há uma cidade que nos fala ao coração, há também filmes que resgatam memórias afetivas sobre experiências inesquecíveis, como as tradições culturais das cidades nordestinas. Catarina Cerqueira, em É tempo de festa nas cidades nordestinas: Viva São João, explora o cinema documentário e as festas juninas, demonstrando que o belo não significa a ausência de contradições. Tal perspectiva também é adotada pelos autores Jorge Nóvoa e Soleni Fressato em "Canção da Bahia, Canção da Liberdade". Liberdade, marginalidade e abandono em Capitães da areia. Novamente os autores utilizam a hipertextualidade das obras de Jorge Amado e as suas representações cinematográficas para descortinar as contradições da capital baiana, a partir da história de meninos de rua que poderiam ser também de qualquer outra grande cidade brasileira

11 A terceira e última parte do livro, Mundos da Barbárie nas Cidades, é a mais densa da obra por explorar diferentes perspectivas da barbárie produzidas no século XX e XXI, seja retomando a memória do stalisnismo em Arrependimento: uma inquietante estranheza, apresentado por Kristian Feigelson, ou pelos segredos do peronismo e a recusa aos silêncios presentes nos cafés e bares em Buenos Aires, discutidos por Heloisa Capel e Leonardo Carmo em $O$ Segredo dos seus olhos: Buenos Aires entre espaços de legitimação $e$ subversão da barbárie.

12 A barbárie expressa na face da violência e da corrupção que marcam as cidades brasileiras cotidianamente, em especial as comunidades periféricas, se fizeram presente na abordagem de Elizabeth Faro, no Extorsão e Silenciamento do Rio de janeiro. Representações em Tropa de Elite 2: o inimigo agora é outro e na brutalidade da tortura, que os olhos se recusem a acreditar que derivam de uma experiência humana, tal qual é descrito por Altair Reis em Imagens da barbárie contemporânea no documentário Fantasmas de Abu Ghraib.

13 Assim como o cinema insisti em nos mostrar que a barbárie é um fenômeno gestado pela lógica do capital, que cotidianamente vai endurecendo o nosso olhar e revelando aspectos sombrios da natureza humana, a literatura também cumpre esse papel e Soleni Fressato, destacando, o realismo fantástico da obra literária de Cem anos de solidão de Gabriel Garcia Marques, explora as contradições e a degradação da cidade imaginária Macondo, fruto da cobiça capitalista e da expropriação tão comum a outras cidades 
reais. A fabulosa cidade de Macondo: uma alegoria da América latina. Da beleza à Barbarie encerra essa obra coletiva, demonstrando que a arte, ao explorar o imaginário e o surreal reproduz e recria simbolicamente todas as cores e dores do real.

14 Como alertou Marc Ferro logo no prefácio, os autores do livro conseguem inalar o perfume das cidades e escutar os seus barulhos. Além disso eles também questionam os seus silêncios e, com olhares atentos e sensíveis, conseguiram desvelar as nuances, por vezes contraditórias, das belezas e das barbáries das cidades. Por isso, a obra Olhares Sensiveis: as Belezas das Cidades e suas Barbáries com sua coletânea textos tão variados torna-se uma leitura não apenas aprazível, mas extremamente necessária.

\section{AUTOR}

CATARINA CERQUEIRA DE FREITAS SANTOS

Professora da Rede Estadual de Educação Básica da Bahia 